Article

\title{
Response of Intestinal Bacterial Flora to the Long-Term Feeding of Aflatoxin B1 (AFB1) in Mice
}

\author{
Xiai Yang, Liangliang Liu, Jing Chen and Aiping Xiao * \\ Institute of Bast Fiber Crops, Chinese Academy of Agricultural Sciences, Changsha 410205, China; \\ yangxiai@caas.cn (X.Y.); liuliangliang@caas.cn (L.L.); 17673116054@163.com (J.C.); xap5@sina.com (A.X.) \\ * Correspondence: xap5@sina.com
}

Academic Editors: Isabelle P. Oswald, Philippe Pinton and Imourana Alassane-Kpembi Received: 9 August 2017; Accepted: 30 September 2017; Published: 12 October 2017

\begin{abstract}
In order to investigate the influence of aflatoxin B1 (AFB1) on intestinal bacterial flora, 24 Kunming mice (KM mice) were randomly placed into four groups, which were labeled as control, low-dose, medium-dose, and high-dose groups. They were fed intragastrically with $0.4 \mathrm{~mL} \mathrm{of} 0 \mathrm{mg} / \mathrm{L}$, $2.5 \mathrm{mg} / \mathrm{L}, 4 \mathrm{mg} / \mathrm{L}$, or $10 \mathrm{mg} / \mathrm{L}$ of AFB1 solutions, twice a day for 2 months. The hypervariable region $\mathrm{V} 3+\mathrm{V} 4$ on $16 \mathrm{~S}$ rDNA of intestinal bacterial flora was sequenced by the use of a high-flux sequencing system on a Miseq Illumina platform; then, the obtained sequences were analyzed. The results showed that, when compared with the control group, both genera and phyla of intestinal bacteria in the three treatment groups decreased. About one third of the total genera and one half of the total phyla remained in the high-dose group. The dominant flora were Lactobacillus and Bacteroides in all groups. There were significant differences in the relative abundance of intestinal bacterial flora among groups. Most bacteria decreased as a whole from the control to the high-dose groups, but several beneficial and pathogenic bacterial species increased significantly with increasing dose of AFB1. Thus, the conclusion was that intragastric feeding with $2.5 \sim 10 \mathrm{mg} / \mathrm{mL}$ AFB1 for 2 months could decrease the majority of intestinal bacterial flora and induce the proliferation of some intestinal bacteria flora.
\end{abstract}

Keywords: mice; aflatoxin B1; intestinal bacterial flora; response

\section{Introduction}

Intestinal microflora play important roles in affecting the health of hosts through many aspects, including nutrition decomposition and transformation, immunity intrusion, biological antagonism and anti-aging [1,2]. Some degree of internal and external stimulation or interference of the body may trigger a change in the numbers or the components of intestinal microflora, cause physiochemical reactions, and lead to diseases [3,4]. Intestinal microflora were proved to be able to bind, transform, degrade, and transfer mycotoxins [5-7]. Some intestinal bacterial strains isolated from intestines and other environments were able to transform and degrade some mycotoxins in vitro [8-10]. Considering the functional influences, scientists attempted to find methods which could balance or optimize intestinal microflora communities to achieve normal or active levels in intestinal tracts and keep the body healthy. For instance, one could feed hosts with curing drugs, nutritional elements, probiotics or symbiotic foods, etc. To a large extent, the normality of intestinal microflora could symbolize the health level of the body [11-13].

Aflatoxins are highly hazardous contaminants in common food and feed, mainly originating from secondary metabolites in Aspergillus flavus and Aspergillus parasiticus [14,15]. Aflatoxin B1 (AFB1) is the predominant type in aflatoxins and was demonstrated to be highly toxic, mutagenic, teratogenic, and carcinogenic to many animals [16,17]. As a potent carcinogen, AFB1 reacts mainly with liver DNA and serum albumin in a dose-dependent manner [18]. Toxicity from AFB1 can lead to a 
reduction in production, hepatotoxicity, nephrotoxicity, disturbance in the gastrointestinal tract and reproduction, immune suppression, and disease susceptibility. Contamination of feed with aflatoxins, especially AFB1, is one of the major concerns in poultry industry $[19,20]$. Because of its high toxicity, strict regulations are placed on foods and feeds containing AFB1, on a world-wide basis [21].

Like most mycotoxins, AFB1 not only damages body organs directly but also disturbs the normal activities of intestinal microflora in animals [22,23]. While previous studies have mainly focused on its toxicology and binding and while some have also attempted to transform and remove AFB1 to decrease the toxicity in some poultry species [24,25], the influential mechanism underlying the effect of AFB1 on intestinal microflora has not been found so far. Based on this investigation, a continuous feeding procedure was performed with KM mice in this study by using AFB1 solutions with various concentrations, which was designed comprehensively according to the dose of chronic aflatoxicosis in mice [26-29]. The research results might lay a foundation for discovering whether the disturbance of intestinal microflora under the toxicity of AFB1 is related to liver cancer or for finding feasible ways to reduce the toxicity through modulating intestinal bacterial flora.

\section{Results}

\subsection{Operational Taxonomic Units (OTUs) and Rarefaction Curves}

The OTUs of each group and the overlapped OTUs among groups were drawn as a Venn picture [30]. The similarity of overlapped OTUs between or among groups was $\geq 97 \%$. There were 167 OTUs contained in all groups, whereas the specific OTUs in the control, low, medium, and high dose groups were 31,16,3, and 7, respectively. Although the high-dose group had slightly higher OTUs than the medium-dose group, the OTUs in each group showed a decrease tendency as a whole (Figure 1).

When the measured Operational Taxonomic Units (OTUs) [31] reached about 250, the rarefaction curves for the control and low-dose groups plateaued. However, when the measured OTUs were about 200 and 150, the rarefaction curves plateaued for the high- and medium-dose groups, respectively (Figure 2). All rarefaction curves of the four groups plateaued, which meant that the majority of sequences were involved in the analysis process for each group. Both OTUs and sequence numbers of the medium-dose group (less than 20,000 reads) were lower than those of the remaining groups (about 20,000 reads) based on Figure 2. The changing trend of the rarefaction curves was consistent with OTUs among groups.

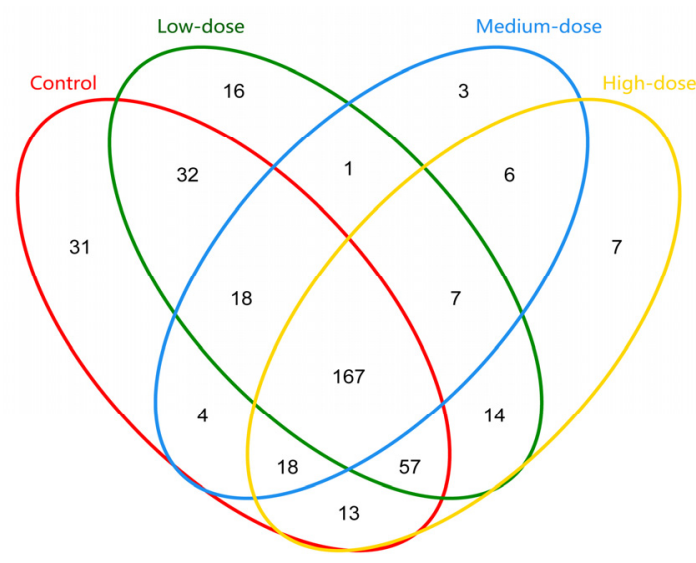

Figure 1. Venn map of OTU distribution in each group and between and among groups (97\% similarity of OTUs). Different colors represent different samples. If, for instance, figure 100 was simultaneously marked in two different circles, this meant that the two samples had the same sequences categorized in the same OTUs, and the OTUs were 100. 


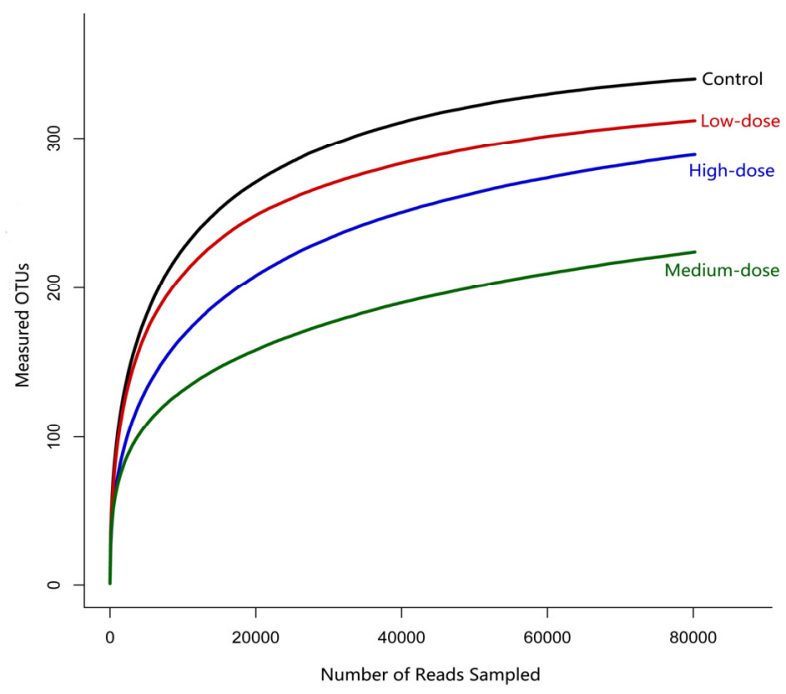

Figure 2. Rarefaction curves (97\% similarity of OTUs). Horizontal ordinate: Sequences sampled randomly; Vertical ordinate: Measured OTUs. Rarefaction curves could estimate the depth of sequencing; the plateau indicates that the measured OTUs could reasonably represent the sampled sequences.

\subsection{Genera and Phyla Performances}

The genus and phylum types and the relative abundances of intestinal bacteria were clustered as a Heatmap [32], where darker colors indicate a higher abundance of the bacterial flora. According to the Heatmap, the control and the low-dose groups had higher abundances and also more types of genera and phyla than the medium- and high-dose groups (Figure 3). The high-dose group had the fewest types of genera. Although there were more genera for both the control and low-dose groups, the genera types differed greatly between the two groups. The two genera with high abundance in the four groups were Lactobacillus and Bacteroides. The four genera with the second highest abundance in the four groups were Candiatus, Desulfovibrio, Bacteroides and Acinetobacter (Figure 3A). Except for the control group, which had an extra phylum Tenericutes, there were 4 phyla with high relative abundances in each group. These 4 phyla were Firmicutes, Bacteroidetes, Proteobacteria and Actinobacteria. There was no evident difference for each phylum among all the groups, and Firmicutes had the highest abundance in each group (Figure 3B).

The genus and phylum types and relative abundances of intestinal bacteria were drawn as column pictures [33]. These pictures contain similar information as in the Heatmap, showing that Lactobacillus and Bacteroides had high abundances in the four groups, while the other 4 genera mentioned in Figure 3 were also present as the second highest. There were visually fewer genera in the high-dose group compared with the rest of groups, and especially with respect to the control group. There was an interesting phenomenon that the abundance of Lactobacillus decreased, but the abundance of Bacteroides increased evidently in the medium-dose group, while the two genera increased, reaching a large proportion in the high-dose group that was nearly the same as in the control group (Figure 4A). With respect to the phyla, more than six phyla were present in the control and the low-dose groups, whereas only 4 phyla were present in the medium- and high-dose groups (Figure 4B). 


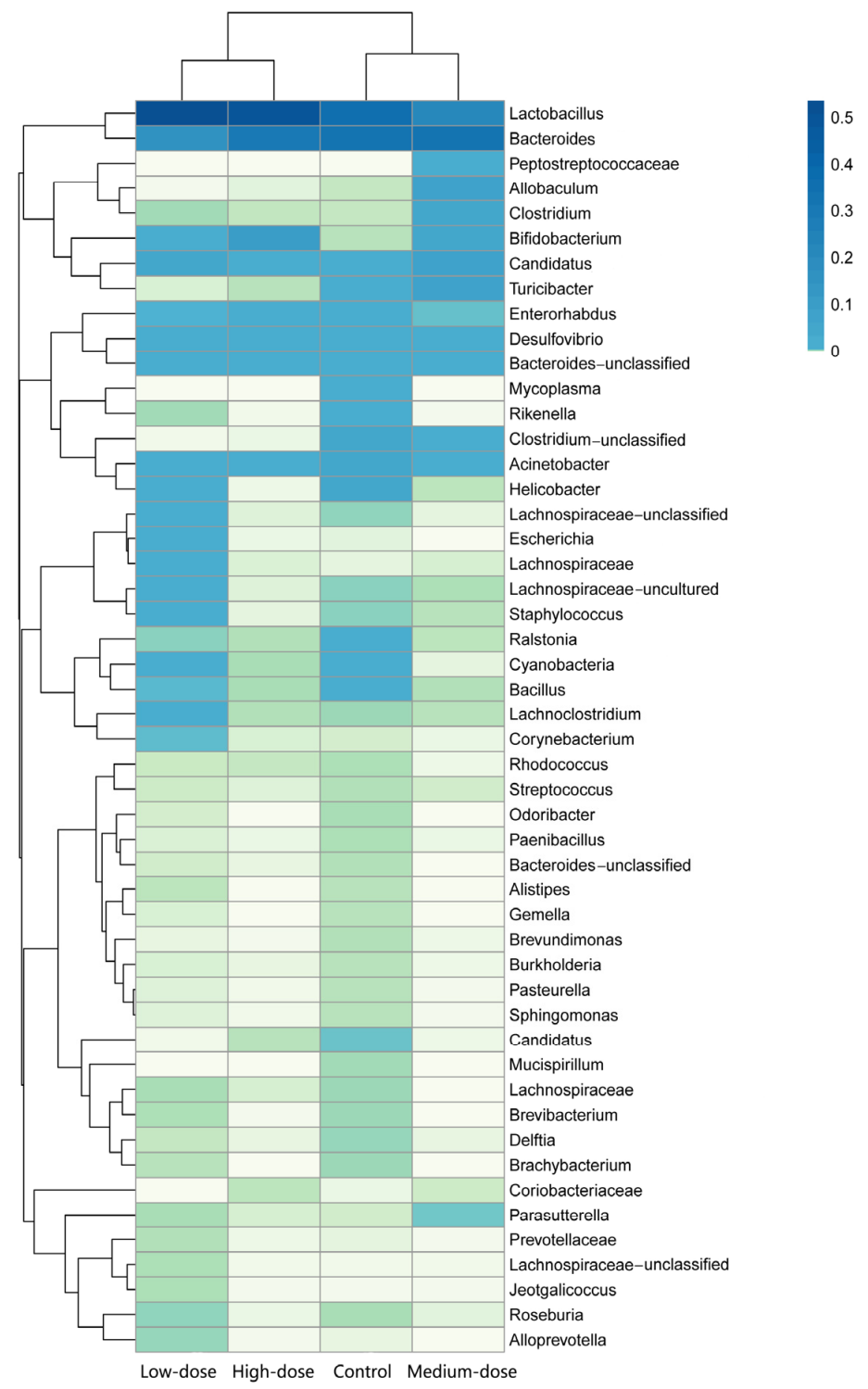

(A)

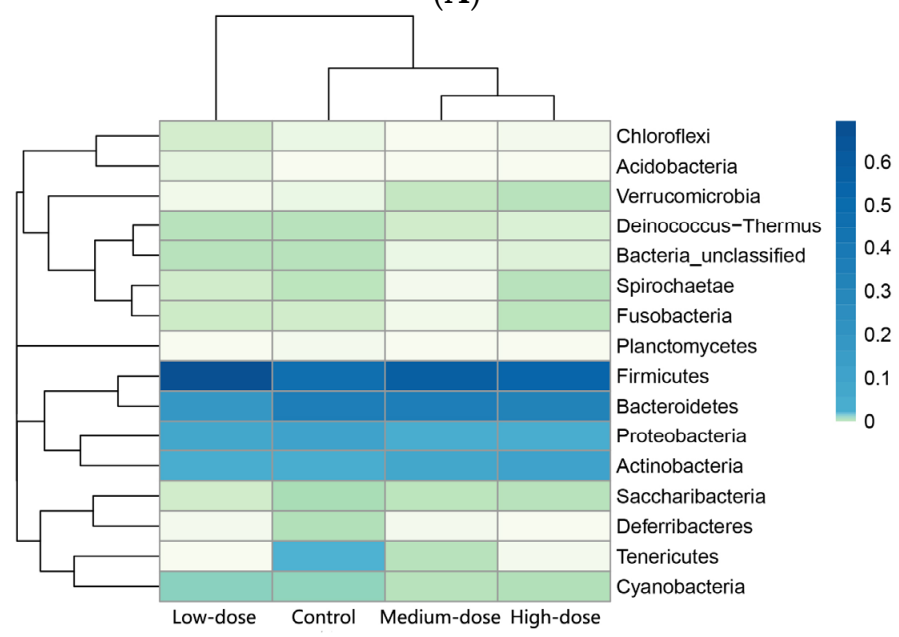

(B)

Figure 3. Heatmap of genus and phylum types and relative abundance of intestinal bacteria flora. (A) Heatmap of genus types; (B) Heatmap of phylum types. Different colors represent the relative abundances of different intestinal bacteria; the darker color indicates higher abundance. 


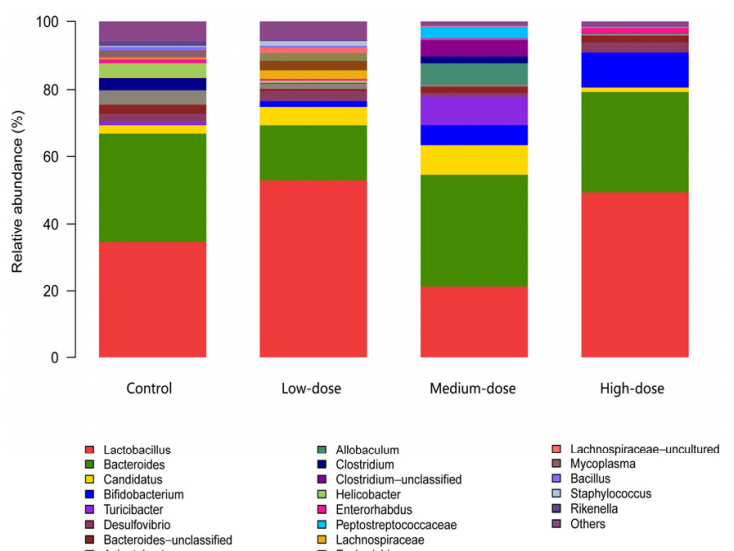

(A)

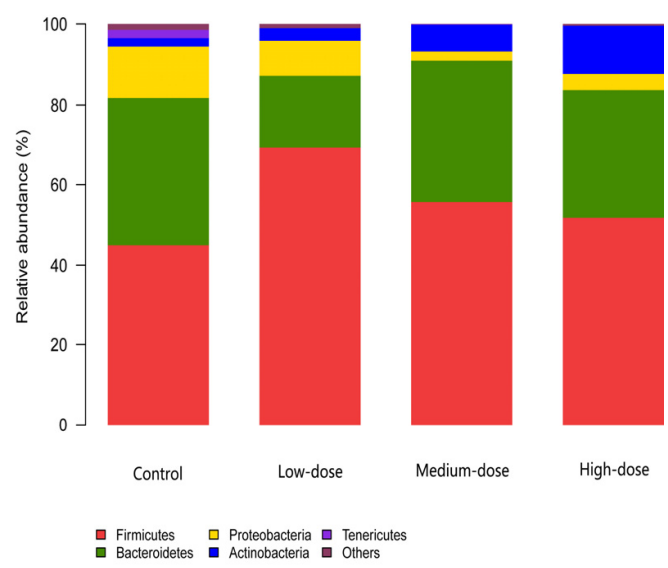

(B)

Figure 4. Column pictures of genus and phylum types and relative abundance of intestinal bacteria. Others: Intestinal bacterial flora with relative abundance $<1 \%$ were included as others. (A) Column pictures of genera; (B) Column pictures of phyla. Different colors represent different intestinal bacteria; the percentage on the vertical ordinate indicates the relative abundance of intestinal bacteria.

\subsection{Phylogenetic Tree}

The phylogenetic tree was built based on the Hierarchical clustering method [34]. The intestinal bacteria of the control and the low-dose groups were clustered together (Figure 5), indicating that most bacteria in the two groups had a relatively close genetic relationship. The intestinal bacteria of the medium- and high-dose groups were clustered together, showing a close genetic relationship.

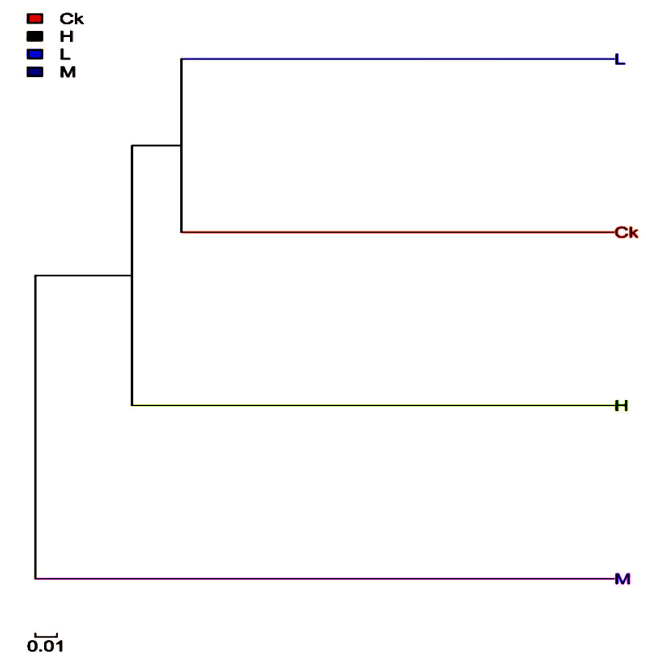

Figure 5. Phylogenetic clustering tree based on the Hierarchical clustering method. Branch size represents the genetic distance between samples; different colors represent different samples.

\subsection{Differences in Relative Abundance of Bacterial Flora}

The significance of the difference in the relative abundance of bacterial flora between groups is shown in Figure 6. Compared with the control, Lactobacillus increased significantly in the low-dose and the high-dose groups but decreased significantly in the medium-dose group. Bacteroides showed a significant decrease in the low-dose group and a slight decrease in the high-dose group, while no evident change occurred in the medium-dose group. Bifidobacterium showed a significant increase in the high-dose group. Candidatus, Turicibacter, Allobaculum, Clostridium, and Peptostreptococcaceae had 
a significant increase in the medium-dose group and then decreased dramatically in the high-dose group. Escherichia and Lachnospiraceae increased significantly in the low-dose group and then decreased dramatically in the medium-dose and the high-dose groups (Figure 6A). The majority of the intestinal bacterial flora at the genus level decreased as a whole, and the results in Figure 6 confirm the results in Figures 3 and 4. At the phylum level, Firmicutes showed a significant increase in all treatment groups, Bacteroidetes showed a significant decrease in the low-dose group, while no evident change occurred in the other two treatment groups, and Actinobacteria showed an increase in all treatment groups, especially in the high-dose group. The remaining phyla showed a decreasing tendency from the control to the high-dose groups (Figure 6B). The statistical data of the relative abundance of intestinal microflora are shown in Table 1.

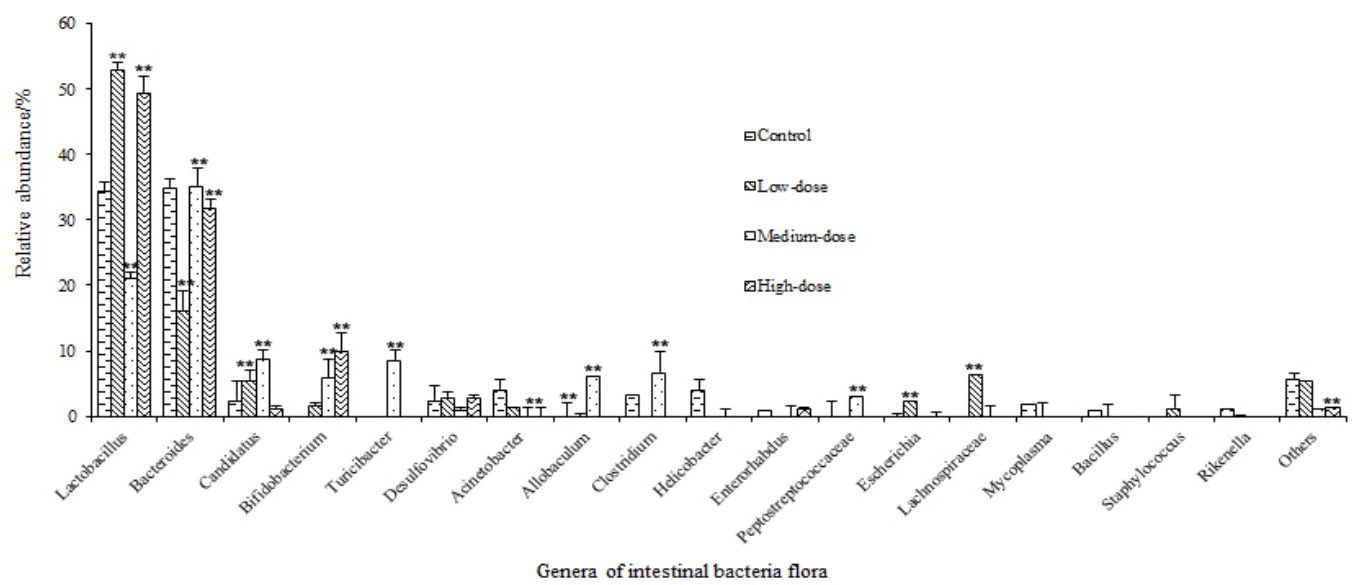

(A)

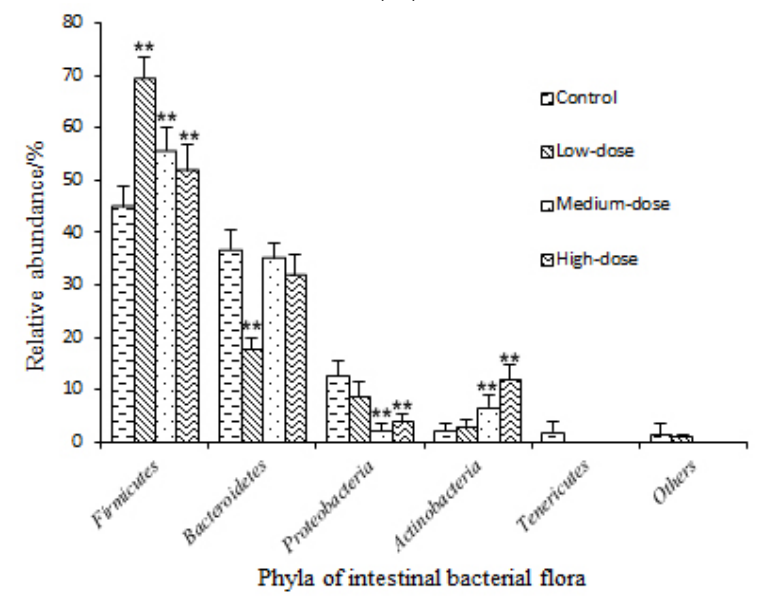

(B)

Figure 6. Difference in relative abundance of intestinal microflora between the control and the treatment groups. (A) Difference in relative abundance of intestinal microflora at the genus level; (B) Difference in relative abundance of intestinal microflora at the phylum level. ${ }^{* *}$ means a significant difference $(p<0.01)$. Data were analyzed using one-way ANOVA. Difference between the control and the treatment groups was assessed by Duncan's test.

Table 1. Relative abundance of intestinal microflora in mice treated with different doses of AFB1.

\begin{tabular}{ccccc}
\hline Taxon & Control & Low-Dose & Medium-Dose & High-Dose \\
\hline Lactobacillus & $34.45 \pm 0.69$ & $52.99 \pm 1.91^{* *}$ & $21.16 \pm 2.01^{* *}$ & $49.40 \pm 2.20$ \\
Bacteroides & $32.32 \pm 1.86$ & $16.27 \pm 1.64^{* *}$ & $33.36 \pm 2.21$ & $29.91 \pm 1.80$ \\
Candidatus & $2.52 \pm 0.10$ & $5.65 \pm 0.13^{* *}$ & $8.80 \pm 0.14^{* *}$ & $1.32 \pm 0.05$ \\
\hline
\end{tabular}


Table 1. Cont.

\begin{tabular}{ccccc}
\hline Taxon & Control & Low-Dose & Medium-Dose & High-Dose \\
\hline Bifidobacterium & $0.11 \pm 0.04$ & $1.71 \pm 0.15$ & $5.98 \pm 0.42^{* *}$ & $10.19 \pm 0.75^{* *}$ \\
Turicibacter & $0.96 \pm 0.06$ & $0.05 \pm 0.01$ & $8.70 \pm 0.33^{* *}$ & $0.11 \pm 0.03$ \\
Desulfovibrio & $2.57 \pm 0.11$ & $2.97 \pm 0.12$ & $1.07 \pm 0.05$ & $2.89 \pm 0.14$ \\
Bacteroides-unclassified & $2.63 \pm 0.10$ & $0.57 \pm 0.05$ & $1.83 \pm 0.06$ & $1.98 \pm 0.10^{* *}$ \\
Acinetobacter & $4.20 \pm 0.01$ & $1.56 \pm 0.01$ & $0.55 \pm 0.01 * *$ & $0.66 \pm 0.01^{* *}$ \\
Allobaculum & $0.07 \pm 0.00$ & $0.08 \pm 0.00$ & $6.20 \pm 0.20^{* *}$ & $0.03 \pm 0.00$ \\
Clostridiium & $3.52 \pm 0.08$ & $0.01 \pm 0.00$ & $4.83 \pm 0.05 * *$ & $0.02 \pm 0.00^{* *}$ \\
Helicobacter & $4.23 \pm 0.15$ & $0.66 \pm 0.01$ & $0.08 \pm 0.00$ & $0.01 \pm 0.00^{* *}$ \\
Enterorhabdus & $1.15 \pm 0.10$ & $0.54 \pm 0.02$ & $0.43 \pm 0.02$ & $1.43 \pm 0.04$ \\
Peptostreptococcaceae-unclassified & $0.00 \pm 0.00$ & $0.00 \pm 0.00$ & $3.22 \pm 0.50 * *$ & $0.00 \pm 0.00$ \\
Lachnospiraceae-unclassified & $0.26 \pm 0.01$ & $2.52 \pm 0.07$ & $0.03 \pm 0.00$ & $0.04 \pm 0.01$ \\
Escherichia & $0.03 \pm 0.01$ & $2.62 \pm 0.05 * *$ & $1.25 \pm 0.02$ & $0.02 \pm 0.00$ \\
Lachnospiraceae & $0.03 \pm 0.00$ & $2.36 \pm 0.12 * *$ & $0.05 \pm 0.01$ & $0.04 \pm 0.00$ \\
Lachnospiraceae-uncultured & $0.30 \pm 0.01$ & $1.64 \pm 0.02$ & $0.14 \pm 0.01$ & $0.04 \pm 0.00$ \\
Mycoplasma & $2.03 \pm 0.07$ & $0.00 \pm 0.00$ & $0.00 \pm 0.00$ & $0.00 \pm 0.00$ \\
Bacillus & $1.04 \pm 0.07$ & $0.48 \pm 0.02$ & $0.12 \pm 0.01$ & $0.17 \pm 0.00$ \\
Staphylococcus & $0.29 \pm 0.00$ & $1.38 \pm 0.12$ & $0.09 \pm 0.00$ & $0.03 \pm 0.00$ \\
Rikenella & $1.31 \pm 0.05$ & $0.18 \pm 0.01$ & $0.02 \pm 0.00$ & $0.05 \pm 0.00 *$ \\
Others & $05.90 \pm 0.17$ & $5.63 \pm 0.15$ & $1.32 \pm 0.05 * *$ & $1.6 \pm 0.08^{* *}$ \\
\hline
\end{tabular}

Each value is the mean \pm standard deviation $(n=3)$. Data were analyzed using one-way ANOVA. Differences between control and treatment groups were assessed by Duncan's test. ${ }^{* *}$ means values are significantly different $(p<0.01)$.

\section{Discussion}

Although knowledge of microflora in animal intestinal tracts is very limited, the view about their mediation and maintenance roles in host health is highly agreeable. Many important immune and metabolic disorders, including diabetes, obesity, behavioral disorders, and chronic inflammation, are known to be partially caused by the imbalance of interactions between host and intestinal microflora [35-37]. It is crucial to keep intestinal microflora in balance for host health.

It is well accepted that the two dominant normal intestinal microflora in mammalians belong to the phyla Firmicutes and Bacteroidetes, which are strict anaerobic bacteria [38]. Bacteroides, Lactobacillus, Streptococcus, Clostridium, Enterococcus, Bifidobacterium, Candidatus, etc. are the main genera with a larger quantity of microflora which inhabit the intestines [39-41]. However, major mycotoxins including deoxynivalenol, zearalenone, ochratoxin A, fumonisin B1 and aflatoxin B1 are proven to be able to disturb the stability of mammalian intestinal microflora [42]. Feeding with a certain dose of deoxynivalenol for 4 weeks by oral gavage increased Bacteroides and Prevotella but decreased Escherichia coli in rat intestines [43]. Zearalenone, given by oral gavage, reduced the total cultivable aerobic bacteria in pig intestines [44]. Ochratoxin A enhanced the Lactobacilliaceae family, increased the facultative anaerobes and decreased the microbial $\alpha$-diversity in rat intestines [45]. Fumonisin B1 changed the similarity between microbial CE-SSCP profiles in pigs after a fumonisin-based feeding [46].

In our study, both genus and phylum showed a decreasing tendency from the control to the high-dose group as a whole, which was consistent with the finding that there was a reduction in microbial diversity in the colon from the healthy rats exposed chronically to AFB1 for 4 weeks [47]. There were about 8 genera with higher relative abundances in the high-dose group, which contained the least genera among all the groups (Figure 3A). Compared with the control group, the high-dose group had about one third of the total genera and nearly half of the total microflora (Figure 4A). There were about 4 phyla in both the medium-dose and the high-dose groups (Figure 4B). Compared with the control group, the high-dose group had about one half of the total phyla. The statistical analysis showed the same decreasing tendency for most bacterial flora except for several special ones (Table 1, Figure 6). However, a chronic exposure to AFB1 could not change the proportion of Firmicutes and Bacteroidetes [47]. 
The two dominant flora in mice were Lactobacillus and Bacteroides. However, their relative abundances were different among the groups. This observation might be explained that AFB1 with different doses disturbed the two dominant bacteria and led to different results. These two dominant bacteria showed similar total proportions in the control, the low-dose, and the high-dose groups but displayed the lowest proportion in the medium-dose group (Figure 4). Different abundance with a similar total proportion under different AFB1 doses meant that these two types of bacteria finally recovered to the normal proportion, even though they were fed with AFB1 at a high dose for 2 months. They showed strong viabilities, indicating that the two bacteria were tolerant and adaptable to a certain dose of AFB1. Wang et al. also found that different bacterial flora had different tolerances to AFB1, three Clostridiales species had the largest increase while 2 Lactobacillales species had the largest decrease with increasing AFB1 dose in their study [47]. Using a cultural method, Galarza-Seeber et al. discovered that the facultative anaerobe (coliforms) population was 10-fold higher than the control in cecum of broilers exposed to AFB1, whereas there was only a numerical non-significant rise observed for other microbial populations [48].

There were five genera with high relative abundances in the medium-dose group but not in other 3 groups, especially not in the high-dose group. They were Peptostreptococcaceae, Allobaculum, Clostridium, Turicibacter, and Cadidatus (Figures 3A and 6A). Among these genera, Clostridium contains several significant human pathogens, including the causative agent of botulism and an important cause of diarrhea [49,50]. A high-fat diet can lead to the expansion of the cluster XI of genus Clostridium, which could produce secondary bile acid, causing a phenotypic change in hepatic stellate cells to secrete proinflammatory cytokines, and eventually resulting in hepatocellular carcinoma in mice [51]. Turicibacter spp. has been strongly associated with immune function and bowel disease [52]. The proportion of Turicibacter was significantly more abundant in Inflammatory Colorectal Polyps (ICRPs)-affected in miniature dachshunds [53]. The high abundances of these bacteria may have resulted from the animals been maintained under unhealthy conditions. However, all these genera were not found in the high-dose group. The mechanism needs to be further explored to understand whether a high dose of AFB1 killed these genera or other factors led to the phenomenon.

Since there are only two research papers published that are relevant to the influence of AFB1 on gut microflora [47,48], more studies are required.

\section{Conclusions}

In conclusion, the intestinal bacterial flora in mice could be strongly disturbed by intragastric feeding with AFB1 solutions ranging from $2.5 \mathrm{mg} / \mathrm{L}$ to $10.0 \mathrm{mg} / \mathrm{L}$ for 2 months. Lactobacillus and Bacteroides were the two dominant bacterial flora, which could be induced to the same level as the control group under a high dose of AFB1 in this study. Nearly two thirds of the total genera and two more phyla finally disappeared. There might be several tolerant, adaptable, and inducible bacterial flora in mouse intestines under a certain dose of AFB1, but this possibility needs be investigated further.

\section{Materials and Methods}

\subsection{Diet Information}

With no antibiotics, hormones, and preservatives, the food ingredients were $27.0 \%$ corn starch, $19.0 \%$ wheat bran, $16 \%$ rice starch, $16.0 \%$ soybean dreg, $13.0 \%$ fish powder, $3.0 \%$ bone powder, $2.3 \%$ yeast powder, $0.5 \%$ salt, $0.1 \%$ compound vitamin and $0.1 \%$ trace elements; sterile water was added to ensure a $10 \%$ water content. After being mixed evenly, the mixture was sterilized at $121{ }^{\circ} \mathrm{C}$ for $20 \mathrm{~min}$ in a high pressure steam sterilizer.

\subsection{AFB1 Solutions Preparation}

The AFB1 stock solution was prepared by dissolving 0.01g AFBI powder (99.9\% of purity, Solarbio Company, Beijing, China) in $500 \mathrm{~mL}$ of $2 \%$ sterile aqueous ethanol. The solution was stirred with a 
magnet stirring bar at $150 \mathrm{rpm}$ under $50^{\circ} \mathrm{C}$ for $30 \mathrm{~min}$ and then diluted with sterile water to reach the concentrations of $2.5 \mathrm{mg} / \mathrm{L}, 4 \mathrm{mg} / \mathrm{L}$, and $10 \mathrm{mg} / \mathrm{L}$.

\subsection{Animal Trial}

All animal experiments were approved by the Animal Care and Use Committee of Institute of Bast Fiber Crops, Chinese Academy of Agricultural Sciences (Changsha, Hunan). A total of 24 KM mice (SPF grade, Silaida Co., Ltd.. Hunan, China) with no specific pathogens were used in this study. Their average weight was about $20 \pm 2 \mathrm{~g}$. Equal numbers of males and females were adaptively fed in a quiet environment at $24{ }^{\circ} \mathrm{C}$ temperature and $65 \%$ humidity. The mice were then randomly divided into 4 groups, which were labeled as the control, low-dose, medium-dose, and high-dose groups. Each group was consisted of an equal number of males and females. The control group was fed intragastrically with sterile water, while the low-dose, the medium-dose, and the high-dose groups were fed intragastrically with $2.5 \mathrm{mg} / \mathrm{L}, 4 \mathrm{mg} / \mathrm{L}$, and $10 \mathrm{mg} / \mathrm{L}$ of AFB1 solutions, respectively. The feeding dosage was $0.4 \mathrm{~mL}$ per mouse each time and 2 times a day for 2 months. Other conventional food was administered normally.

\subsection{Sample Collection}

The animals were killed by cervical dislocation and dissected aseptically on a laminar flow bench after the feeding treatment was over. Small intestinal contents (from jejunum to rectum) were collected from 2 randomly chosen mice (one male and one female) in each group, then stirred evenly with a sterile glass rod under a sterile environment, and considered as one replicate. Three replicates were used to analyze intestinal bacteria.

\subsection{Intestinal Bacterial Flora Information}

The total DNA was extracted from the obtained intestinal contents according to the instruction of the FastDNA ${ }^{\circledR}$ Spin Kit for Feces (MP Company, CA, USA) and then tested by electrophoresis on a 1\% agarose gel. After being recycled and purified with AxyPrepDNA (Axygen Company, CA, USA), the bands were amplified with primers 338F: ACTCCTACGGGAGGCAGCA and 806R: GGACTACHVGGGTWTCTAAT, which were specifically designed for testing the hypervariable region $\mathrm{V} 3+\mathrm{V} 4$ zones of intestinal bacteria DNA. The PCR reaction mixture contained $4 \mu \mathrm{L}$ of $5 \times$ Fast Pfu buffer, $2 \mu \mathrm{L}$ of $2.5 \mathrm{mM}$ dNTPs, $0.8 \mu \mathrm{L}$ of $5 \mu \mathrm{M}$ Forward Primer, $0.8 \mu \mathrm{L}$ of $5 \mu \mathrm{M}$ Reverse Primer, $0.4 \mu \mathrm{L}$ FastPfu Polymerase, $0.2 \mu \mathrm{L}$ BSA, and $10 \mathrm{ng}$ Template DNA. Dd $\mathrm{H}_{2} \mathrm{O}$ was added to reach the final volume to $20 \mu \mathrm{L}$. The reaction conditions as follows: an initial denaturing cycle at $95^{\circ} \mathrm{C}$ for $3 \mathrm{~min}$, with 28 cycles, denaturation at $95^{\circ} \mathrm{C}$ for $30 \mathrm{~s}$, annealing at $55^{\circ} \mathrm{C}$ for $30 \mathrm{~s}$, and extension at $72{ }^{\circ} \mathrm{C}$ for $45 \mathrm{~s}$, with a final extension step at $72{ }^{\circ} \mathrm{C}$ for $10 \mathrm{~min}$. Electrophoresis on $2 \%$ agarose gels was used to test the PCR products, the gene library was built, and the sequences were analyzed by Frasergene company (Wuhan, Hubei, China) with the Miseq Illumina System.

\subsection{Statistical Analysis}

SPSS software 22.0 (IBM Corp, Armonk, NY, USA) was used to analyze the significance of differences in the relative abundances of intestinal bacterial flora between groups.

Acknowledgments: The acknowledgments are given to Ministry of Agriculture of the People's Republic of China for funding this work (the Project No. GJFP2016010).

Author Contributions: Aiping Xiao and Xiai Yang conceived and designed the experiments; Xiai Yang and Jing Chen performed the experiments; Xiai Yang and Liangliang Liu analyzed the data and wrote the paper.

Conflicts of Interest: The authors declare no conflicts of interest. 


\section{References}

1. Lu, L.; Walker, W.A. Pathologic and physiologic interactions of bacteria with the gastro intestinal epithelium. Am. J. Clin. Nutr. 2001, 73, 1124S-1130S. [PubMed]

2. Blaut, M.; Clavel, T. Metabolic diversity of the intestinal microbiota: Implications for health and disease. J. Nutr. 2007, 137, 751S-755S. [PubMed]

3. Cani, P.D.; Neyrinck, A.M.; Fava, F.; Knauf, C.; Burcelin, R.G.; Tuohy, K.M.; Gibson, G.R.; Delzenne, N.M. Selective increases of bifidobacteria in gut microflora improve high-fat-diet-induced diabetes in mice through a mechanism associated with endotoxaemia. Diabetologia 2007, 50, 2374-2383. [CrossRef] [PubMed]

4. Croswell, A.; Amir, E.; Teggatz, P.; Barman, M.; Salzman, N.H. Prolonged impact of antibiotics on intestinal microbial ecology and susceptibility to enteric salmonella infection. Infect. Immun. 2009, 77, 2741-2753. [CrossRef] [PubMed]

5. Eriksen, G.S.; Pettersson, H.; Johnsen, K.; Lindberg, J.E. Transformation of trichothecenes in ileal digesta and faeces from pigs. Arch. Anim. Nutr. 2002, 56, 263-274. [CrossRef]

6. Wang, J.C.; Tang, L.L.; Glenn, T.C.; Wang, J.S. Ameliorating effects of Bacillus subtilis ANSB060 on growth performance, antioxidant functions, and aflatoxin residues in ducks fed diets contaminated with aflatoxins. Toxicol. Sci. 2016, 150, 54-63. [CrossRef] [PubMed]

7. Young, J.C.; Zhou, T.; Yu, H.; Zhu, H.; Gong, J. Degradation of trichothecene mycotoxins by chicken intestinal microbes. Food Chem. Toxicol. 2007, 45, 136-143. [CrossRef] [PubMed]

8. Kollarczik, B.; Gareis, M.; Hanelt, M. In vitro transformation of the Fusarium mycotoxins deoxynivalenol and zearalenone by the normal gut microflora of pigs. Nat. Toxins 1994, 2, 105-110. [CrossRef] [PubMed]

9. Niderkorn, V.; Boudra, H.; Morgavi, D.P. Binding of Fusarium mycotoxins by fermentative bacteria in vitro. J. Appl. Microbiol. 2006, 101, 849-856. [CrossRef] [PubMed]

10. Hathout, A.S.; Aly, S.E. Biological detoxification of mycotoxins: A review. Ann. Microbiol. 2014, 64, $905-919$. [CrossRef]

11. Vitali, B.; Ndagijimana, M.; Cruciani, F.; Carnevali, P.; Candela, M.; Guerzoni, M.E.; Brigidi, P. Impact of a synbiotic food on the gut microbial ecology and metabolic profiles. BMC Microbiol. 2010, 10, 1471-2180. [CrossRef] [PubMed]

12. Qi, H.W.; Xiang, Z.T.; Han, G.Q.; Chen, D.W. Effects of different dietary protein sources on cecal microflora in rats. Afr. J. Biotechnol. 2011, 10, 3704-3708.

13. Chassard, C.; Scott, K.P.; Marquet, P.; Martin, J.C.; Del'homme, C.; Dapoigny, M.; Flint, H.J.; Bernalier-Donadille, A. Assessment of metabolic diversity within the intestinal microbiota from healthy humans using combined molecular and cultural approaches. FEMS Microbiol. Ecol. 2008, 66, 496-504. [CrossRef] [PubMed]

14. Wogan, G.N. Aflatoxins as risk factors for hepatocellular carcinoma in humans. Cancer Res. 1992, 52, 2114s-2118s. [PubMed]

15. Windham, G.L.; Hawkins, L.K.; Williams, W.P. Aflatoxin accumulation and kernel infection of maize hybrids inoculated with Aspergillus flavus and Aspergillus parasiticus. World Mycotoxin J. 2010, 3, 89-93. [CrossRef]

16. Bennett, J.W.; Klich, M. Mycotoxins. Clin. Microbiol. Rev. 2003, 16, 497-516. [CrossRef] [PubMed]

17. Cuccioloni, M.; Mozzicafreddo, M.; Barocci, S.; Ciuti, F.; Re, L.; Eleuteri, A.M.; Angeletti, M. Aflatoxin B1 misregulates the activity of serine proteases: Possible implications in the toxicity of some mycotoxins. Toxicol. In Vitro 2009, 23, 393-399. [CrossRef] [PubMed]

18. Sabbioni, G. Chemical and physical properties of the major serum albumin adduct of aflatoxin B1 and their implications for the quantification in biological samples. Chem. Biol. Interact. 1990, 75, 1-15. [CrossRef]

19. Rawal, S.; Kim, J.E.; Coulombe, R.J. Aflatoxin B1 in poultry: Toxicology, metabolism and prevention. Res. Vet. Sci. 2010, 89, 325-331. [CrossRef] [PubMed]

20. Mughal, M.J.; Peng, X.; Kamboh, A.A.; Zhou, Y.; Fang, J. Aflatoxin B1 induced systemic toxicity in poultry and rescue effects of Selenium and Zinc. Biol. Trace Elem. Res. 2017, 178, 292-300. [CrossRef] [PubMed]

21. Liu, B.H.; Hsu, Y.T.; Lu, C.C.; Yu, F.Y. Detecting aflatoxin B1 in foods and feeds by using sensitive rapid enzyme-linked immunosorbent assay and gold nanoparticle immunochromatographic strip. Food Control. 2013, 30, 184-189. [CrossRef] 
22. He, J.; Zhang, K.Y.; Chen, D.W.; Ding, X.M.; Feng, G.D.; Ao, X. Effects of maize naturally contaminated with aflatoxin B1 on growth performance, blood profiles and hepatic histopathology in ducks. Livest. Sci. 2013, 152, 192-199. [CrossRef]

23. Wache, Y.J.; Valat, C.; Postollec, G.; Bougeard, S.; Burel, C.; Oswald, I.P.; Fravalo, P. Impact of deoxynivalenol on the intestinal microflora of pigs. Int. J. Mol. Sci. 2009, 10, 1-17. [CrossRef] [PubMed]

24. El-Nezami, H.; Mykkänen, H.; Kankaanpää, P.; Salminen, S.; Ahokas, J. Ability of Lactobacillus and Propionibacterium strains to remove aflatoxin B, from the chicken duodenum. J. Food Prot. 2000, 63, 549-552. [CrossRef] [PubMed]

25. Gratz, S.; Täubel, M.; Juvonen, R.O.; Viluksela, M.; Turner, P.C.; Mykkänen, H.; El-Nezami, H. Lactobacillus rhamnosus Strain GG Modulates Intestinal Absorption, Fecal Excretion, and Toxicity of Aflatoxin B1 in Rats. Appl. Environ. Microbiol. 2006, 72, 7398-7400. [CrossRef] [PubMed]

26. Egbunike, G.N.; Emerole, G.O.; Aire, T.A.; Ikegwuonu, F.I. Sperm production rates, sperm physiology and fertility in rats chronically treated with sublethal doses of aflatoxin B1. Andrologia 1980, 12, 467-475. [CrossRef] [PubMed]

27. Wild, C.P.; Garner, R.C.; Montesano, R.; Tursi, F. Aflatoxin B1 binding to plasma albumin and liver DNA upon chronic administration to rats. Carcinogenesis 1986, 7, 853-858. [CrossRef] [PubMed]

28. Hinton, D.M.; Myers, M.J.; Raybourne, R.A.; Franckecarroll, S.; Sotomayor, R.E.; Shaddock, J.; Warbritton, A.; Chou, M.W. Immunotoxicity of aflatoxin B1 in rats: Effects on lymphocytes and the inflammatory response in a chronic intermittent dosing study. Toxicol. Sci. 2003, 73, 362-377. [CrossRef] [PubMed]

29. Wogan, G.N.; Newberne, P.M. Dose-response characteristics of aflatoxin B1 carcinogenesis in rats. Cancer Res. 1968, 27, 2370-2376.

30. Fouts, D.E.; Szpakowski, S.; Purushe, J.; Torralba, M.; Waterman, R.C. Next generation sequencing to define prokaryotic and fungal diversity in the bovine rumen. PLoS ONE 2012, 7, e48289. [CrossRef] [PubMed]

31. Amato, K.R.; Yeoman, C.J.; Kent, A.; Righini, N.; Carbonero, F.; Estrada, A.; Gaskins, H.R.; Stumpf, R.M.; Yildirim, S.; Torralba, M.; et al. Habitat degradation impacts black howler monkey (Alouatta pigra) gastrointestinal microbiomes. ISME. J. 2013, 7, 1344-1353. [CrossRef] [PubMed]

32. Jami, E.; Israel, A.; Kotser, A.; Mizrahi, I. Exploring the bovine rumen bacterial community from birth to adulthood. ISME J. 2013, 7, 1069-1079. [CrossRef] [PubMed]

33. Oberauner, L.; Zachow, C.; Lackner, S.; Högenauer, C.; Smolle, K.H.; Berg, G. The ignored diversity: Complex bacterial communities in intensive care units revealed by $16 \mathrm{~S}$ pyrosequencing. Sci. Rep. 2013, 3, 1413-1422. [CrossRef] [PubMed]

34. Noval, M.R.; Burton, O.T.; Wise, P.; Zhang, Y.Q.; Hobson, S.A.; Lloret, M.G.; Chehoud, C.; Kuczynski, J.; DeSantis, T.; Warrington, J.; et al. A microbita signature associated with experimental food allergy promotes allergic senitization and anaphylaxis. J. Allergy Clin. Immunol. 2013, 131, 201-212. [CrossRef] [PubMed]

35. Musso, G.; Gambino, R.; Cassader, M. Interactions between gut microbiota and host metabolism predisposing to obesity and diabetes. Annu. Rev. Med. 2011, 62, 361-380. [CrossRef] [PubMed]

36. Tremaroli, V.; Bäckhed, F. Functional interactions between the gut microbiota and host metabolism. Nature 2012, 489, 242-249. [CrossRef] [PubMed]

37. Lee, W.J.; Hase, K. Gut microbiota-generated metabolites in animal health and disease. Nat. Chem. Biol. 2014, 10, 416-424. [CrossRef] [PubMed]

38. Lozupone, C.A.; Stombaugh, J.I.; Gordon, J.I.; Jansson, J.K.; Knight, R. Diversity, stability and resilience of the human gut microbiota. Nature 2012, 489, 220-230. [CrossRef] [PubMed]

39. Salzman, N.H.; De, J.H.; Paterson, Y.; Harmsen, H.J.; Welling, G.W. Analysis of 16S libraries of mouse gastrointestinal microflora reveals a large new group of mouse intestinal bacteria. Microbiology 2002, 148, 3651-3660. [CrossRef] [PubMed]

40. Dick, L.K.; Bernhard, A.E.; Brodeur, T.J.; Domingo, J.W.S.; Simpson, J.M.; Walters, S.P.; Field, K.G. Host distributions of uncultivated fecal Bacteroidales bacteria reveal genetic markers for fecal source identification. Appl. Environ. Microbiol. 2005, 71, 3184-3191. [CrossRef] [PubMed]

41. Shenghua, G.; Dandan, C.; Jinna, Z.; Xiaoman, L.; Kun, W.; Liping, D.; Yong, N.; Xiaolei, W. Bacterial community mapping of the mouse gastrointestinal tract. PLOS ONE 2013, 8, e74957.

42. Robert, H.; Payros, D.; Pinton, P.; Theodorou, V.; Mercier-Bonin, M.; Oswald, I.P. Impact of mycotoxins on the intestine: Are mucus and microbiota new targets? J. Toxicol. Environ. Health B Crit. Rev. 2017, 20, $249-275$. [CrossRef] [PubMed] 
43. Saint-Cyr, M.J.; Perrin-Guyomard, A.; Houée, P.; Rolland, J.G.; Laurentie, M. Evaluation of an oral subchronic exposure of deoxynivalenol on the composition of human gut microbiota in a model of human microbiotaassociated rats. PLoS ONE 2013, 8, e80578. [CrossRef] [PubMed]

44. Piotrowska, M.; Sliżewska, K.; Nowak, A.; Zielonka, L.; Zakowska, Z.; Gajęcka, M.; Gajęcki, M. The effect of experimental fusarium mycotoxicosis on microbiota diversity in porcine ascending colon contents. Toxins 2014, 6, 2064-2081. [CrossRef] [PubMed]

45. Guo, M.; Huang, K.; Chen, S.; Qi, X.; He, X.; Cheng, W.H.; Luo, Y.; Xia, K.; Xu, W. Combination of metagenomics and culture-based methods to study the interaction between ochratoxin $\mathrm{A}$ and gut microbiota. Toxicol. Sci. 2014, 141, 314-323. [CrossRef] [PubMed]

46. Burel, C.; Tanguy, M.; Guerre, P.; Boilletot, E.; Cariolet, R.; Queguiner, M.; Postollec, G.; Pinton, P.; Salvat, G.; Oswald, I.P.; et al. Effect of low dose of fumonisins on pig health: Immune status, intestinal microbiota and sensitivity to Salmonella. Toxins 2013, 5, 841-864. [CrossRef] [PubMed]

47. Wang, J.; Tang, L.; Glenn, T.C.; Wang, J.S. Aflatoxin B1 induced compositional changes in gut microbial communities of male F344 rats. Toxicol. Sci. 2016, 150, 54-63. [CrossRef] [PubMed]

48. Galarza-Seeber, R.; Latorre, J.D.; Bielke, L.R.; Kuttappan, V.A.; Wolfenden, A.D.; Hernandez-Velasco, X.; Merino-Guzman, R.; Vicente, J.L.; Donoghue, A.; Cross, D.; et al. Leaky gut and mycotoxins: Aflatoxin B1 does not increase gut permeability in broiler chickens. Front. Vet. Sci. 2016, 3, 10. [CrossRef] [PubMed]

49. Bartlett, J.G. Narrative review: The new epidemic of Clostridium difficile-associated enteric disease. Ann. Intern. Med. 2006, 145, 758-764. [CrossRef] [PubMed]

50. Pépin, J.; Routhier, S.; Gagnon, S.; Brazeau, I. Management and outcomes of a first recurrence of Clostridium difficile-associated disease in Quebec, Canada. Clin. Infect. Dis. 2006, 42, 758-764. [CrossRef] [PubMed]

51. Yoshimoto, S.; Loo, T.M.; Atarashi, K.; Kanda, H.; Sato, S.; Oyadomari, S.; Iwakura, Y.; Oshima, K.; Moria, H.; Hattori, M.; et al. Obesity-induced gut microbial metabolite promotes liver cancer through senescence secretome. Nature 2013, 499, 97-101. [CrossRef] [PubMed]

52. Allen, J.M.; Miller, M.E.B.; Pence, B.D.; Whitlock, K.; Nehra, V. Voluntary and forced exercise differentially alters the gut microbiome in C57BL/6J mice. J. Appl. Physiol. 2015, 118, 1059-1066. [CrossRef] [PubMed]

53. Igarashi, H.; Ohno, K.; Horigome, A.; Fujiwara-Igarashi, A.; Kanemoto, H.; Fukushima, K.; Odamaki, T.; Tsujimoto, H. Fecal dysbiosis in miniature dachshunds with inflammatory colorectal polyps. Res. Vet. Sci. 2016, 105, 41-46. [CrossRef] [PubMed] 